\title{
IMPRESIONES SONORAS DEL AULA-ZOOM
}

\author{
Sound Impressions of the Zoom-Classroom
}

SEBASTIÁN PLÁ

Universidad Nacional AutónOMA de MÉXICO (MÉXICO)

SEBASTIANPLA@GMAIL.COM

ORCID: 0000-0001-8613-1607

DOI: https://doi.org/10.5565/rev/mitologias.851

vol. 25 | enero 2022 | 51-67

Recibido: 18/10/2021 | Aceptado: 17/01/2021

\section{Resumen:}

Se presenta aquí una serie de impresiones sobre los paisajes sonoros producidos por el aulazoom durante la pandemia en México. El resultado es la paradójica conclusión de que la mutación de los sonidos escolares demuestra el proceso contemporáneo en el que la escuela ha perdido el monopolio de la escolarización, así como la cada vez mayor dificultad de esta institución para crear un lugar para habitar en lo común. El texto interrelaciona estudios del sonido, historia de la cultura escolar y teoría educativa contemporánea para analizar este fenómeno liminal entre escuela, tecnología y cotidianidad. Las impresiones se dividen en dos apartados. En el primero nombro los sonidos tónicos que crean los fondos sonoros en el aula-zoom. En el segundo trabajo las relaciones sónicas a partir de tres metáforas: voz/voces, mutis/mutismo y escucha/escuchas. La recopilación de información se hizo a partir de un diario de campo y las grabaciones de las sesiones en Zoom durante tres semestres en la licenciatura y el posgrado de Pedagogía de la Universidad Nacional Autónoma de México.

\section{Palabras clave:}

Paisaje sonoro, cultura escolar, escuela digital, aula-zoom, pandemia 


\section{Abstract:}

This text presents a series of impressions on the soundscapes produced by the zoomclassroom during the pandemic in Mexico. The study of sound in the educational digital environment shows how the school has lost control of the process of schooling. At the same time, it depicts the increasing difficulty of this institution to create a place to inhabit the commonplace. The text interrelates sound studies, the history of the grammar of schooling, and contemporary educational theory to study this liminal phenomenon between school, technology, and everyday life. The impressions are divided into two sections. First, I name the keynotes created by the sonic environment in the zoom-classroom. In the second section, I write about sonic relationships based on three metaphors: voice/voices, mute/mutism, and listening / listening(s). The collection of information was made from a field diary and the recordings of the sessions during three semesters in the undergraduate and postgraduate studies in Pedagogy at the National Autonomous University of Mexico during the closure of face-to-face education because of the sanitary measures to combat the Covid pandemic.

\section{Keywords:}

Soundscape, Grammar of schooling, Digital school, Zoom-Classroom, Pandemic 


\section{Acontecimiento}

Abro micrófono. Hablo y doy por hecho que me escuchan, pero no hay certeza. Cierro micrófono. Ella abre micrófono. Habla, comenta la lectura y pide disculpas por el aviario que suena intenso sobre ella. Cierra micrófono. Abro micrófono. Clic, rueda de desplazamiento, teclado, clic. Digo que es bonito. Ella abre micrófono. Pero a veces es demasiado ruidoso, da pena, comenta. Cierra micrófono. Hablo e imagino que cada estudiante tiene sus propios ruidos ambientales, ajenos a los míos, que estamos en espacios sonoros diferentes y que esto es una clase sin ambiente acústico común. Como mucho, lo hacemos colectivo unos instantes, quizá dos o tres a la vez, pero por lo general primero uno y luego otro. Yuxtapuestos. No sé, concluyo. Señal electroacústica doble. Clic, clic, clic. Estudiantes entran al espacio virtual. Cierro micrófono. Él abre micrófono y comparte su voz, sostiene que no lo ha pensado pero que parece ser cierto. Apaga micrófono enseguida, temeroso de que un ruido invada ese no lugar digital. Silencio compartido. Alguien más abre micrófono y su voz se mezcla con el metal del organillo que suena unos pisos más abajo, en un callejón que yo no puedo ver. Cierra micrófono. Alguien más abre micrófono. Habla, pero sus palabras se ralentizan y dejan una reverberación eléctrica, exclusiva de un edificio cibernético. Abro micrófono. Clic, rueda de desplazamiento, teclado, clic. Un avión encima mío, solo arriba de mí. Cierro micrófono. No sé y pregunto: ¿cómo es el ambiente auditivo en un aula virtual? ¿Qué tipos de sonidos nuevos son normados dentro del aula? ¿Cuáles parecen nuevos, pero no lo son? ¿Qué condiciones auditivas posibilita o impide la geometría del aula-zoom? ¿Qué nueva aula anuncian estos ruidos? ¿Qué relación hay entre nuevo espacio auditivo escolar y la sociedad que lo envuelve? ¿Es este ruido yuxtapuesto una nueva fase del capitalismo educativo? ¿Qué registro puedo hacer como docente, escucha y hablante inmerso en esta sonoridad fragmentada? En fin, ¿cómo interpreto este nuevo paisaje sonoro? Abro micrófono. Demasiadas preguntas, sentencio con voz clara en el estudio de mi casa. Nadie entiende, nadie escuchó. El micrófono estaba cerrado. Clic, rueda de desplazamiento, teclado, clic. Cierro sala.

\section{Introducción}

Dos años como maestro virtual, más tiempo que el cierre de escuelas producido por la pandemia. Casi cuatro semestres. El primero como tutor y tres periodos continuos como tutor y docente de dos cursos, uno en licenciatura y otro en posgrado. En el último semestre, el segundo de 2021, se sumó un tercer curso, uno internacional, latinoamericano, mixto: a distancia y virtual. Todos esos meses hablando, escuchando, preguntando, registrando esos ecos, reverberaciones, voces, silencios y ruidos que crean mi nueva aula. Todavía es un interregno educativo en México y en buena parte de América Latina. Vivido como extenso en el ahora, pero en el tiempo histórico de la larga duración, en el futuro de este presente, tal vez sea solo un instante que nada cambió. Sin embargo, si en el "ruido se leen los códigos de la vida, las relaciones entre los hombres" (Attali, 1995: 15) y "los ruidos de una sociedad van por delante de sus imágenes y de sus conflictos materiales" (Attali, 1995: 22), vale pensar los nuevos ruidos áulicos como fractura o tal vez como premonición de lo que la escolarización en cuanto práctica cultural será. El sonido en el aula, como marcas y señales de nuestro tiempo, va más allá del mero proceso educativo dentro de la escuela. Representa también nuevas formas de socialización nacionales y globales que son producidas en lugares alejados de la escuela, pero resignificadas y generadas a su vez por la propia práctica escolar. En este sentido, un horizonte de la presente investigación es indagar sobre los nuevos sonidos en el aula como forma de socialización y de construcción de lo común en el capitalismo contemporáneo.

Ese horizonte todavía se ve en lontananza. Por el momento, trataré de dar algunos pasos hacia allí, iniciando con lo más básico: la descripción o, un poco más subjetivo, la impresión. No pretendo teorizar sobre el sonido ni hacer estudios acústicos o sonoros. Mi interés es utilizar el sonido que se produce en un aula virtual para que, con base en él o más bien a través de él, me ubique en un espacio 
teórico liminal en el que la reflexión educativa sobre la escuela encuentre perspectivas de futuro. Para ello, retomaré de los estudios del sonido la idea de paisaje sonoro, entendido en su sentido más lato y original de entorno acústico (Schafer, 2013: 24); de la historia de la educación las investigaciones sobre la cultura escolar como conjunto de prácticas, rituales y objetos que producen sentido de la escuela (Viñao, 2002); y de las discusiones contemporáneas de la filosofía de la educación se recuperará la institución escolar como tiempo de suspensión (Maaschelein y Simons, 2014) y lo educativo de la acción educativa (Biesta, 2016). Esto me permitirá usar el sonido en el aula-zoom para interpretar cómo la yuxtaposición y la imbricación de espacios sonoros en un no lugar crean instantes sónicos compartidos e incontables momentos personales que singularizan el vínculo pedagógico y rompen, a su vez, su componente colectivo. Este paisaje auditivo termina produciendo relaciones educativas que prescriben nuevos y no tan nuevos sentidos de lo común.

Esta conjunción se basa en cuatro elementos sobrepuestos entre si que no pretenden ser ni jerárquicos ni explicativos. Digamos que lo que intento en este primer momento es plasmar una impresión que de sentido a una galería de cuadros yuxtapuestos en la que cada uno está inmerso en un ambiente sonoro propio. Una primera pregunta es ¿qué sonidos componen un paisaje sonoro de un aula virtual? Este registro se basa en la tipología de Schafer (2013) de sonidos tónicos, señales y marcas sonoras, aunque solo utilizaré los dos primeros. Es el primer elemento de mi composición. Los siguientes tres son: voz/voces, mutis/mutismo y escucha/escuchas. Cada uno de ellos ayudan a responder a la pregunta ¿qué prácticas normalizadoras y socializadoras pueden describirse a partir del paisaje sonoro en un salón de clases digital? Las tres metáforas se ubican en la tensión permanente entre la singularización del proceso escolar y la escuela como lugar común, separado de la vida productiva y familiar.

Las preguntas y los elementos se basan en un referente empírico muy particular: el cierre de las escuelas en México desde marzo de 2020 como causa de la pandemia de Covid-19. Se entiende escuela como una institución social que comparte prácticas, relaciones y sentidos básicos que van desde el preescolar hasta la universidad. Por mencionar uno solo que atraviesa todos los niveles, se puede fijar la atención en la relación asimétrica de poder entre docente y estudiantes. En la educación superior, donde centro mi estudio, la clausura de la presencialidad escolar ha durado ya veintiún meses. Las luchas por reabrir las escuelas no han sido sencillas y un importante movimiento contrario a la presencialidad, comandado principalmente por docentes de todos los niveles educativos, se ha negado sistemáticamente a regresar a los edificios escolares. Mi universidad, la Universidad Nacional Autónoma de México, a pesar de su pluralidad interna, es una de las instituciones más reacias a la presencialidad. No quiero discutir el carácter legal o la violación al derecho a la educación que supone esta postura, sino mencionar que mi referente empírico, la docencia virtual en la educación superior, está inmerso en esta coyuntura política, sanitaria y educativa. Al momento, noviembre 2021, no hay claridad de que mi universidad regrese a clases presenciales totales en el semestre que inicia en 2022. Asimismo, mi referente empírico se toma de este largo periodo de escolarización virtual, en el que he dedicado parte de mi docencia a registrar en un diario de campo y a grabar en las sesiones los ruidos, las palabras y los ecos de mis clases. Todas estas sesiones se impartieron en y a través de la plataforma Zoom. ${ }^{1}$ En un segundo momento, gracias a que dicha plataforma crea también un archivo exclusivamente sonoro, me dediqué a escuchar y registrar nuevamente los sonidos en el aula excluyendo la vista, para contrarrestar el ocularcentrismo de nuestra tradición científica positiva. Estos sonidos fueron organizados en la tipología de Schafer y en las tensiones metafóricas señaladas más arriba. Como se verá, el carácter yuxtapuesto e imbricado y por tanto no-

\footnotetext{
${ }^{1}$ El estudio se realizó en Zoom porque fue la plataforma que mi universidad puso a mi disposición. Sin embargo, considero que lo interpretado aquí para Zoom puede ser extendido a Google Meet, Webex u otras plataformas de comunicación digital. Zoom, Webex o Meet son marcas diferentes que diseñan una misma geometría áulica, un mismo marco pedagógico: galería visual de rostros o bustos y la yuxtaposición de ambientes sonoros. Zoom es mi referente, pero no tiene particularidad simbólica en relación a las otras. Todas son plataformas privadas que crean las mismas condiciones de posibilidad que permiten pensar y actuar en las relaciones pedagógicas de ciertas maneras, al mismo tiempo que excluye a otras. El nombre de aulazoom incluye a todas estas plataformas.
} 
narrativo de los ambientes sonoros en el aula digital es esencial. No ha sido sencillo y espero que el resultado sea más halagüeño que mi propia experiencia.

He organizado este texto en tres grandes apartados. En el primero expongo con un poco más de profundidad qué entiendo por paisaje sonoro a partir de Schafer, así como los reajustes conceptuales realizados por otros autores en décadas posteriores y lo tejo con nociones de la escuela como lugar y tiempo de suspensión. Ahí mismo describo la teoría educativa contemporánea sobre escolarización y los elementos que definen a la cultura escolar llamada también gramática escolar (Tyack y Cuban, 1995). En el segundo apartado describo los sonidos tónicos. En el tercero, denominado control sónico escolar, despliego mis impresiones auditivas a partir de las tres metáforas: voz/voces, mutis/mutismo y escucha/escuchas. Cierro el texto con algunas impresiones finales.

\section{Aula y paisaje sonoro}

El aula en la escuela y el aula virtual o digital son lugares. Si se prefiere, son un lugar y un no lugar (Augé, 2008), ${ }^{2}$ un lugar físico y un lugar desmaterializado (Han, 2021), un lugar que se habita con los cinco sentidos y un lugar que se habita solo con dos, un lugar en el que todos estamos en el mismo tiempo y espacio con otros y un lugar en el que se está con otros en diferentes espacios y tiempos (Lovink, 2020; Abrahams y Pinheiro, 2020). Ambos son aulas porque están creados o usados para el acto de enseñar, de aprender y, si se tiene la posibilidad, de educar. Como espacios escolares, crean sus propios ambientes sonoros. Uno, el físico, comparte sonidos, armoniza pausas, considera ruidos a las mismas señales sonoras, los silencios se intercambian y la perspectiva de fondo y primer plano hace del momento de inmersión presencia. El otro lugar, el aula virtual, sobrepone espacios auditivos en los que se pueden compartir una interrupción sonora pero no el mismo fondo sonoro, intercambia voces, pero no necesariamente pausas, corta los sonidos lo que deja al habla sin "glissando" y yuxtapone ruidos particularizados a los espacios de cada participante en una línea continua, sin evolución narrativa, que hace del momento áulico una inmersión fragmentada, repleta de ausencia. Es un paisaje sonoro escolar nuevo, público y privado simultáneamente, increíblemente extenso y dramáticamente particularizado y es un espacio auditivo en el que el balizado que lo limita ha sido trasgredido.

La desaparición del umbral entre interior y exterior disloca una de las piedras de toque que forma a lo escolar. La escuela, como la estoy entendiendo aquí, es una institución moderna. Surge en la bisagra de los siglos XVIII y XIX impulsada por el pensamiento ilustrado, la revolución industrial y el nacionalismo. Sin embargo, estos tres elementos reordenan y dan continuidad a uno de los principios fundacionales de la escuela o, en los términos de Simons y Masschelein (2014), lo que hace a la escuela, escuela. Para estos autores, el término griego scholè (tiempo libre) es clave. La scholè, en la Grecia clásica, define un espacio que permite crear un tiempo libre e igualitario: "La escuela surge como una concreta materialización y espacialización del tiempo que literalmente separa o saca a los alumnos del (desigual) orden social y económico (el orden de la familia, pero también el orden de la sociedad en su conjunto) y los lleva al lujo de un tiempo igualitario" (Masschelein y Simons, 2014: 30). Es un espacio que produce

\footnotetext{
${ }^{2}$ El lugar, el espacio y el no lugar pertenecen a una discusión compleja que me desvía demasiado del tema. De modo sintético, entiendo el lugar como lo físico e histórico que da identidad, es aquello que se habita; el espacio lo defino como el conjunto de relaciones que los componen (De Certeau, 2000: 129), exista o no el lugar físico; y entiendo no lugar a partir de Marc Augé (2008), para quien los no lugares son espacios de tránsito que no se configuran como lugares antropológicos. El no lugar existe como lugar y nunca es en forma pura, dado que recompone lugares que le preexistieron (Augé, 2008: 84). Un aeropuerto es el ejemplo más emblemático de ello, pero también lo son los hospitales. La diferencia con un aula-zoom radica en la evolución tecnológica del no lugar, por lo que este no lugar digital ha logrado desligarse de un lugar físico, como sería el edificio escolar o el aeropuerto. De ahí que en un mismo no lugar sin materialidad física podamos seguir idénticas normas de uso para una cátedra universitaria, una junta ejecutiva o una reunión familiar. En cierta medida, es lo que Han denominó lo desmaterializado de la hipercultura (Han, 2021).
} 
una suspensión, una desaparición o borramiento temporal del orden social. Esto es posible al marcar un adentro y un afuera que permite liberar a estudiantes, docentes y materia de estudio del tiempo productivo y del tiempo familiar (Masschelein y Simons, 2014: 33). La escuela es escuela porque no es la vida cotidiana, ni la vida en familia, ni la vida del trabajo. La escuela es ese espacio y ese tiempo que pone a todos en la misma condición de libertad para relacionarse de una manera particular con el saber: el estudio (Pinar, 2016). La pandemia dislocó esto (Plá, 2020a y 2020b, en prensa).

La materialización de ese espacio es producto, en buena medida, del siglo XIX (Dussel y Caruso, 2006), cuando la vida material de la escuela, sus prácticas y sus códigos disciplinares (Cuesta, 1998) cobraron forma. En otras palabras, cuando la cultura escolar se asentó en las sociedades occidentales primero y después se universalizó. Los diseños curriculares, la disposición de las bancas en un salón de clase, los ritos escolares (McLaren, 1995); la relación de poder docente-estudiante, la legitimación de la función educativa atribuida a los distintos saberes curriculares que prescriben lo que debe ser aprendido y enseñado (Pinar, 2016); la imposición velada o no de principios morales (Jackson, 1996); los objetos diseñados exclusivamente para la escuela y las formas en que se usan en ese tiempo liberado de la vida cotidiana son prácticas comunes a lo largo y ancho de los estados nacionales contemporáneos. Y también son los paisajes sonoros en y de la escuela, con sus chicharras que marcan los tiempos, los momentos de silencio compartido, el permiso de hablar o callar, la música permitida y enseñada, el barullo colectivo de desaprobación o el susurro lo suficientemente alto para el oído del docente, pero a la vez tan débil que no permite identificar su fuente son producto y producen la cultura escolar (Gershon, 2017; Gershon y Appelbaum, 2019). Este orden sónico, como el resto de la cultura escolar, es un paisaje sonoro cultural y político, tanto en la producción del ruido como en el acto de escucha (Samuels et al., 2010).

El paisaje sonoro hace referencia a un entorno acústico (Schafer, 2013). ${ }^{3}$ Es todo lo que suena a nuestro alrededor y que somos capaces de escuchar, consciente o inconscientemente. Esta idea fundacional está asentada en la concepción de un contorno sonoro que está ahí y que de una u otra manera escuchamos. Un paisaje se mira desde la distancia, no se está en él. Sin embargo, escuchar un paisaje sonoro es un acto inclusivo, no exclusivo como sería el mirar. La mirada fija la atención en un punto convergente, el oído atrapa lo divergente, lo que no está secuenciado, a menos que sea la música, entendida como ruido organizado (Attali, 1995). No se observa el sonido, se escucha. En su definición más lata, el paisaje sonoro del aula-zoom es todo lo que escuchamos durante una sesión educativa a través de la plataforma Zoom u otras similares.

Sin embargo, la idea de paisaje ha sido cuestionada dentro de los estudios del sonido por lo menos en tres aspectos. El primero es su carácter natural, que considera el paisaje como algo externo al propio acto de escuchar y, por tanto, a la dimensión subjetiva y política de dicho acto (Samuels et al. 2010). Una segunda crítica, no distante de la anterior y esgrimida sobre todo por la historia cultural, profundiza sobre el carácter simultáneo de un ambiente sonoro físico y las formas de percibir ese ambiente, entre el mundo físico y la cultura que lo escucha (Corbin, 1998; Thompson, 2012). En esta relación, la mirada cultural del paisaje sonoro implica las formas en que escuchamos, la relación entre el ambiente sonoro y el escuchador y las condiciones sociales que dictan quién escucha qué. Los estudios de Alain Corbin (1998) sobre las campanas en el campo francés muestran la relación entre el sonido, el orden social y la interdependencia de la cultura con el sonido, dado que se configuran mutuamente. Este último ejemplo

\footnotetext{
${ }^{3}$ Los estudios del sonido y la educación han estado dirigidos básicamente al control de ruido para favorecer el aprendizaje. En estos estudios una definición muy utilizada es la de Anderson (2004), que se refiere a los aspectos auditivos del ambiente de aúlicos. El objetivo de estas indagaciones es mejorar el paisaje sonoro para hacer más eficiente los procesos de adquisición del conocimiento, incluso en aquello que han propuesto interpretaciones semióticas (Cárdenas-Soler y Martínez-Chaparro, 2015) caen en este rubro. Otras visiones, más apegadas a la dimensión ecológica de Schafer, se centran en la educación auditiva que promueve un ear cleaning (Schafer, 2013) o limpieza sonora que combate la contaminación ambiental. En mi caso, me inclino más por una mirada cultural que escuche el sonido como socialización de nuevas formas de relación educativa en contextos educativos virtuales.
} 
tiene relación con la escuela, en cuanto la campana escolar regula tiempos, transiciones y ritos. La antropología fue un paso más allá y estudia cómo la organización del sonido en habla y canto es una forma de producción del conocimiento que derivó en el concepto acuñado por Steven Feld (2013) de acustemología. Finalmente, una tercera crítica viene a partir de la noción de espacio que implica el paisaje sonoro de Schafer, en el que el sonido compone un espacio determinado, omitiendo cómo el espacio produce el sonido (Eisenberg, 2015; Helmreich, 2010). Esta última crítica es vital para escuchar una clase a través del aula-zoom, pues justo es un aula que procesa los sonidos exteriores y produce un espacio sonoro virtual. Esto es lo que llevó a Helmreich a acuñar el término de transduction que implica la mediación individual desde "el agua exterior al aire interior" (Helmreich, 2010: 10) o, podemos extender la idea en mi referente empírico, del barullo exterior al pitido computarizado.

La relación entre educación y estudios del sonido es, por un lado, larga y, por el otro, escueta. La educación del oído en la escuela ha sido parte de los fundamentos educativos de la escolarización. La enseñanza de la música es su ejemplo más notable. Pero también hay muchos estudios, algunos basados en la hermosa idea de Schafer de ear cleaning (2013), sobre la que desarrolló una didáctica específica (Schafer, 1998) y otros preocupados por el efecto negativo del ruido en el aula sobre los aprendizajes escolares. Pero la relación sonido e investigación educativa es novel, pues poco hay de estudios del sonido y la cultura escolar. Algunos textos al respecto pueden verse en el pedagogo canadiense Ted Aoki (2012) y en los trabajos de Walter Gernshon $(2017,2013)$, quien, ubicado en los estudios del currículum, más específicamente en la teoría del currículum desarrollada por William Pinar, sostiene que todo sonido es educativo y que desde el sonido podemos cuestionar las composiciones curriculares que escuchan únicamente al docente. Dos ideas más que me interesa recuperar de Gernshon son el sonido en la escuela como una forma de beingknowingdoing es decir, de ser, de saber y de hacer en la vida escolar y, finalmente, el sonido como currículum es algo organizado que da sentido al mundo escolar (Gernshon, 2017). Esta organización incluso puede ser cartografiada bajo criterios de raza, espacio, lugar e identidad (Gernshon, 2013: 2011). Esto es parte de lo que Gernshon denomina currículum sonoro. En este texto, es la clase social uno de los criterios que subyacen a la desigualdad educativa reflejada por los sonidos escolares y digitales en la educación virtual. ${ }^{4}$

De esta manera, aquí entiendo el paisaje sonoro de un aula-zoom como entorno acústico, la producción de sonidos específicos de esta escolarización, las condiciones sociales que produce y condiciona qué se permite escuchar y que no, la escuela como forma que organiza y crea la geometría que permite o prescribe ciertos sonidos y la forma en que cada sujeto percibe, escucha, dicho paisaje sonoro. Como se verá, este ambiente sónico es fragmentado, increíblemente singularizado y, al mismo tiempo, profundamente escolar. No es una simple adición de sonidos en un espacio y tiempo determinado. Es el resultado de combinaciones dinámicas e inestables de elementos físicos (sonoros), digitales (Zoom), ambientales (cada lugar) y perceptuales (sujetos) en constante relación y determinación mutua, que producen un ensamble único para un instante pero que, escuchado durante varias sesiones, encuentra un tono estable de la repetición escolar.

\footnotetext{
${ }^{4} \mathrm{El}$ presente estudio retoma el problema de desigualdad de clase para analizar los espacios sonoros. Esto no implica que sea el único. Por ejemplo, como me hizo notar una o un evaluador del capítulo, la desigualdad de género también es un aspecto relevante, como lo son también las condiciones laborales, pues muchos docentes vivieron situaciones similares a las que aquí describo sobre los alumnos. Otra muy notable en México es la desigualdad entre lo rural y lo urbano. Con base en esto, reconozco la intersección de los diferentes componentes de las desigualdades educativas en un aula-zoom, pero por motivos de espacio me limito a la clase social.
} 


\section{Sonidos tónicos}

Hay que empezar por lo material, por lo que produce el sonido y en el aula-zoom no es otra cosa que el mundo digital y su soporte. En un país tan desigual como México, el soporte digital como materialización de la enseñanza implica necesariamente que el ambiente auditivo de cada estudiante y las posibilidades de compartirlo con el resto del grupo están marcados por la clase social. Lo que yo escucho como docente, en la sala de mi casa, con un computadora personal, no es lo mismo que el entorno sonoro de un estudiante con audífonos conectados a un teléfono celular mientras atiende simultáneamente el puesto familiar de chiles en un mercado del oriente de la Ciudad de México o que una estudiante con una computadora de escritorio cuyo ventilador crea una sonido estacionario en la colonia Balbuena, justo debajo de la ruta de los aviones prontos a aterrizar en el aeropuerto internacional Benito Juárez. Cada espacio sonoro en el que se fragmenta el aula digital condiciona las posibilidades de estudio, de atención y de aprendizaje. Por eso, reducir la desigualdad educativa a la conectividad en la educación a distancia universitaria generada por la pandemia es insuficiente. El estudio del sonido, con sus ruidos y señales tónicas compartidas a medias en el aula digital, refleja la desigualdad educativa en las condiciones mismas de cada lugar y sus posibilidades o no de convertir a un dormitorio, una sala o un mercado en una escuela.

Los sonidos tónicos son ubicuos. Son el ejemplo más claro del currículum sonoro como pura presencia. No los escuchamos conscientemente. En el aula-zoom el soporte básico de lo digital y de nuestra vida cotidiana es la electricidad. Esta establece el ritmo o el ruido profundo sobre el que se desarrolla el habla en Zoom. En la playa, el sonido tónico son las olas reventando en la orilla; junto a una autopista, el flujo vehicular continuo; en una sala de clases-zoom, el siseo digital. Estos sonidos, estos fondos influyen "de manera honda y omnipresente en nuestro comportamiento y humor" (Schafer, 2013: 27) y, se puede agregar, en nuestras relaciones pedagógicas. Dado que los escuchamos inconscientemente, la mejor manera de percatarse de ellos es cuando se callan. El zumbido eléctrico se identifica cuando un apagón lo silencia y el espacio sonoro cobra mayor fidelidad, por lo que cada sonido en la ciudad se comienza a escuchar de otra manera, más nítida, particularizada, calma. En el aula-zoom eso no pasa, no puede suceder, pues requiere de la electricidad para ser clase, para poder producir su acto pedagógico. Es un siseo sedimentado en nuestros cuerpos, presos nuestros oídos a él. Este sonido tónico produce cansancio porque estamos imbuidos por la intensidad eléctrica. El zumbido, la vibración permanente sin evolución alguna, "es un narcótico para el intelecto" (Schafer, 2013: 126). Si hay estática, escuchamos diferente y, por tanto, pensamos, estudiamos y aprendemos de manera diferente. La electricidad es la base sonora sobre la que se montan el resto de los abotagamientos producidos por Zoom (Lovink, 2020).

Los sonidos tónicos se ven salpicados de fondos diversos, ajenos al propio espacio digital y al espacio áulico. Quizá otro sonido tónico dentro de la individualización del fondo auditivo, dependiendo del dispositivo de conexión, sea el ruido intermitente producido por el hardware: el clic o chasquido del ratón, los engranes de plástico de la rueda de deslizamiento y el arrastre del ratón sobre la superficie de la mesa o la alfombrilla. También, los dedos que golpean las teclas en las computadoras son otro sonido tónico. Estos sonidos tienen una presencia física inmediata. Su origen es identificable y son producto de los movimientos limitados de nuestro cuerpo o más bien de nuestras manos y brazos. Movimientos producidos por el propio objeto sonoro y el uso del cuerpo que exige.

Si el fondo sonoro es algo que todos escuchamos y por tanto nos introduce en un espacio común, el ritmo del teclado o el clic del ratón es, en la educación virtual, individual. Y más aún, cada fondo sonoro es particular, solo compartido unos instantes al abrir el micrófono para hablar. Este acto yuxtapone sonidos tónicos distantes del objeto sonoro que los produce. Es lo que Schafer (2013) denominó esquizofonía. Los fondos sonoros se siguen unos con otros. Así como la galería de rostros en Zoom ordena a los participantes en filas y columnas sin orden aparente, lo mismo sucede con el paisaje sonoro. Cada participante tiene su propio ambiente sonoro. Por eso, una aula-zoom no es narrativa, sino es como el zumbido eléctrico, continuo y sin evolución, en presencia estacionaria. Una representación escrita de 
los instantes compartidos y que constituyen el paisaje sonoro de toda el aula-zoom sería más o menos así: pájaros/avión/gritos infantiles-lavadora automática-chorro de agua-vajilla contra vajilla/ladrido/alarma automóvil/avión-martillazos. No es ni puede ser una narración, pues está compuesta de yuxtaposiciones e imbricaciones auditivas.

Por supuesto, cada una de estas impresiones está comandada por la voz del participante. Esto desdibuja los límites entre el sonido urbano, los ruidos familiares y el espacio acústico escolar. No hay tiempo ni espacio libre de la vida cotidiana. Este borramiento es representativo de la actualidad, donde la escuela ha ido perdiendo su centralidad como espacio educativo. Incluso más allá, lo que está perdiendo es el monopolio de la escolarización. Esto modifica las jerarquías educativas, las formas de socialización y las relaciones de poder dentro del aula. También cuestiona la propia escuela como ejercicio de poder. En otras palabras, al desdibujarse los espacios sonoros y los espacios físicos, lo que tenemos es un desvanecimiento de la escuela como institución de lo común, para convertirse en una mezcla entre lo urbano y lo escolar, entre lo privado y lo público. Esta pluralidad de fondos, paradójicamente, es una pérdida a la diversidad auditiva en los salones de clase: el paisaje sonoro áulico producido por lo que sucede dentro de ella, la ecología sonora del entorno e incluso los sonidos naturales que acompañan las estaciones, se desvanecen en el repiqueteo de los timbres digitales.

A lo anterior hay una excepción. La voz sin fondo. O lo que podríamos llamar el efecto cabina. Dueño de unos audífonos que cancelan el ruido, el habla estudiantil o docente se asemeja más a un locutor de radio que a estudiantes y docentes participando en un salón de clases. Porque en la cabina no hay ruido y, por el contrario, en un aula siempre hay ruidos más allá de los que cada individuo produce. En un momento caracterizado por el silencio escolar, digamos un examen, suena el grafito marcando el papel, la fricción de la mezclilla sobre la banca de plástico, el pasar ansioso de las hojas, el carraspeo de una garganta seca, la respiración propia y la ajena. El estudiante o el docente en cabina, en cambio, solo comparte su voz. Auditivamente, no colabora con los demás. Vacía el espacio sonoro o por lo menos lo reduce al mínimo. Es un momento nítido, de alta fidelidad, de la soledad que produce la relación pedagógica en el aula-zoom. Pero este caso, por lo menos en mi trabajo de campo, no es mayoritario, por lo que puede pensarse como un punto de fuga hacia un futuro en el que nuestros ambientes sonoros educativos estén compuestos solo por nuestra voz. Educación del habla, no de la escucha.

\section{Control sónico escolar}

La escuela es un espacio de control. En los sueños de los ingenieros sociales, la escuela sería una microsociedad que se organiza con base en inputs y outputs que permiten dirigir el proceso de escolarización hacia fines eficientemente planificados. El sonido en su interior está meticulosamente regulado con campanas que normalizan los comportamientos y los momentos del habla, del silencio o del barullo; el espacio está diseñado para ocultar los sonidos corporales o en su caso establecer dónde se pueden o no emitir; y la posición jerárquica en su interior define quien le grita a quien: el director al docente, el docente al estudiante, el estudiante a su par o al estudiante más débil. En sentido inverso, los escolanovistas pretendieron, y aún pretenden, otras escuelas en las que el murmullo dentro de un aula no signifique desorden sino trabajo colaborativo, en las que los timbren no suenen cada hora para no cortar el desarrollo natural de una actividad didáctica y en la que el silencio sea producto del propio niño, no de una imposición externa (Montessori, 2014). ${ }^{5}$ Sea a partir del control exógeno o de la interiorización de la

\footnotetext{
${ }^{5}$ No es tema de este ensayo, pero la Escuela Nueva establece otro tipo de relación con el sonido. El centro es la voz y el silencio en primera instancia se entiende como la imposición de un orden autoritario que impide el desarrollo natural de los niños (Montessori, 2014; Freinet, 1978). Esto no niega el valor del silencio, más bien valora otro tipo. María Montessori estudia su importancia en el aprendizaje y el recogimiento. Desarrolla, dentro de su educación de los sentidos, "La lección del silencio" (2014: 240). Ahí es importante que el niño pueda aprender a conocerlo e inteririorizarlo, como camino hacia la concentración
} 
norma, el sonido escolar es producto y productor de la escuela. De esta manera, la escuela impone y crea tipos de sonidos por un lado y, por otro, otorga y socializa su sentido. Permite ciertos lenguajes, ciertas formas de enseñanza, ciertas posibilidades de conocimiento, ciertos ruidos y distintos modos de silencio, al mismo tiempo que impide y proscribe otros. El aula-zoom no es excepción. Veamos tres ejemplos.

\section{Voz/Voces}

La docencia es básicamente una práctica oral. Zoom no elimina esta característica. Más aún, la potencia, dado que reduce la vista y desaparece el resto de los sentidos, por lo menos los sentidos en un espacio compartido. La voz del docente es tanto algo que hay que desarrollar y modular como el símbolo jerárquico de la educación autoritaria. Contra esa voz, autores como Célestine Freinet (1978) se rebelaron desde la didáctica y desde la educación popular, Paulo Freire sostuvo la importancia de la palabra y la voz de los oprimidos (2017). Pero en educación y más allá, la voz es cuerpo y materialidad que histórica y culturalmente se significa en pluralidad. Quien tiene voz posee individualidad, agencia, autoría y poder, mientras que quien no la tiene carece de todos estos atributos. Hay otras voces, íntimamente relacionadas con lo educativo y la socialización, como la voz interior. También la tienen las colectividades y las divinidades: la voz de los estudiantes, la voz del pueblo, la voz de Dios (Weidman, 2015: 232), a las que se le suman las voces no humanas, como la de Anonymous o la de los GPS que guían nuestro tránsito de un lugar a otro. Hoy en educación, la voz del estudiante es la del derecho a la subjetividad o más correctamente, del sujeto soberano. La educación empodera al dar voz.

Con el aula-zoom la voz escolar se reproduce, se imbrica y se singulariza. Reproduce la cultura escolar comúnmente denominada tradicional. El docente conserva la voz dominante, ahora favorecida por el micrófono apagado de sus estudiantes, y se la da a quien obediente levanta la mano en formato emoticón. La aplicación dispone el orden de manos levantadas en la barra lateral de la derecha. El docente conserva el poder de la voz y de designación de quien puede hablar o no. Asimismo, las hay múltiples en el cuchicheo, de la afirmación o el rechazo unísono desaparecen, por lo menos a oídos del docente. En este sentido, la voz como interpelación, como sorpresa y como disrupción de parte de los estudiantes queda proscrita. En la escuela virtual la palabra de los estudiantes dentro del aula se fragmenta en el número de asistentes. Esto no niega la posibilidad de otros espacios de organización, como sería el chat o la comunicación por otros dispositivos. Lo que quiero decir es que la clase síncrona mediada por una plataforma regula las voces. Tan es así, que el micrófono de Zoom prioriza la voz potente y grave por sobre la suave y tranquila, creando un orden de voces que privilegian, por lo general, a los hablantes masculinos (Søren Pold en Lovink, 2020).

También imbrica y en este proceso rompe con la descontextualización característica de lo escolar. Con excepción del estudiante en cabina, el resto de los participantes en una aula-zoom está inmerso en ambientes sonoros particularizados. Esto yuxtapone sonidos, lo que produce a su vez una sobreposición de voces. Déjenme ser más claros. Como ya mencioné, la cultura escolar basa sus elementos distintos en la descontextualización de su práctica de la vida cotidiana. El espacio crea un tiempo de suspensión de la vida cotidiana y de la productividad. Ahí se emiten voces propias que producen, por ejemplo, la voz

y el aprendizaje. La diferencia con el modelo tradicional radica, entonces, en que el niño en el modelo Montessori lo hace por sí mismo y no por la presión heterónoma. Es un ejemplo más intenso de la sociedad del disciplinamiento, la gubernamentalidad y del efecto de la escolarización como dispositivo de control (Dussel y Carusso, 2006). Muy diferente aparece en la educación popular de Paulo Freire (2017), donde lo que predomina dentro de la educación bancaria es la cultura del silencio impuesta, que no es otra cosa que la proscripción de la voz de los oprimidos. Actualmente, hay una revalorización del saber callar como parte sustantiva de los procesos educativos de corte conservador por un lado y, por otro, en respuesta a los excesos de las interpretaciones contemporáneas de la escuela nueva. En este último grupo, el silencio es una forma activa de aprendizaje (Luri, 2020). 
académica. Cuando hablamos en un aula universitaria lo hacemos con palabras, tonos e intenciones que se ajustan a la ciencia en cuestión. El paisaje sonoro escolar que produce el saber descontextualizado (Chevalard, 1991; Baquero, Diker y Frigerio, 2007). Este ejercicio pretende igualdad (Masschelein y Simons, 2014), por lo que en cierta medida vela la procedencia cultural de los sujetos hablantes. Pero la palabra mediada por lo digital se declara en una especie de rebeldía no intencionada, pues Zoom permite el ingreso de sonidos tónicos característicos de la clase social de los estudiantes. Con ellas se imbrican los sonidos del trabajo (un mercado), la familia (un niño llorando) y de trayectos (tráfico) que tienen cualquier destino menos un salón de clases. Esta imbricación de sonidos múltiples en cada espacio individual sonoro rompe la descontextualización escolar. Con ella, se corre el riesgo de perder la suspensión necesaria para pensar, por lo menos pensar escolarmente.

La imposibilidad del aula-zoom radica en el encuadre de una actividad colectiva en la singularidad casi absoluta de sus participantes. Rompe la comunidad escolar. Parte se debe a que no hay espacio, no hay itinerarios que nos lleven a él, no hay posibilidad de habitarlo de forma conjunta. Quizá el ejemplo más notorio de lo anterior sea la intimidad. No la emisión de una voz íntima que comparte un pensamiento profundo sobre una materia de estudio, sino la intimidad mostrada de la cama sin tender de la habitación docente o estudiantil. La voz se emite en ese contexto, negando un conjunto de voces que emiten al unísono una aprobación o un rechazo. Es la intimidad que habita en otro espacio y hace de su experiencia escolar algo único, no compartido El fenómeno de hablar desde la cama no es nuevo, el teléfono nos lo permite hace mucho tiempo y los teléfonos inteligentes nos permiten juntar voz e imagen, pero el acto de hablar por teléfono no pretende ser un espacio compartido. Uno sabe que no está en la pizzería y por eso llama para que se le entregue el pedido en la puerta de su casa. En cambio, en el aulazoom estamos ahí, con otros, pero no hay voz colectiva, simultánea, a menos que se planee y controle desde un dispositivo central. La singularidad es total, porque habitamos otros espacios en el momento en que hacemos la escuela digital. En otras palabras, las voces se yuxtaponen unas a otras, pero están inhabilitadas parar convertirse en una voz. Por eso, funciona mejor en posgrado que en bachillerato o en la escuela primaria donde lo común de la escuela es insustituible.

\section{Mutis/mutismo}

Los sonidos son tan diversos que su propia ausencia implica sinnúmero de matices. La ausencia no es silencio y el silencio en el aula-zoom escolar es mutis. Es el acto de callar, de hacer callar e, incluso, de salir en silencio de la escena. Mutis, en cuanto metáfora y no categoría, permite fijar el oído en el ejercicio de poder que establece quien calla y quien no, así como en la acción de resistencia estudiantil de guardar silencio y salir del aula de manera en apariencia discreta, pero informada al docente por medio de una señal huidiza, fugaz, sin reverberación. Mutis tiene además la derivación en mutismo, silencio voluntario o no, que en la escuela es tan común. Callo porque no quiero hablar. Callo porque no me dejan hablar. Callo porque tengo miedo de hablar. Callo, dirá Freire, por la imposición de la cultura del silencio (Freire, 2017). Hay demasiados tipos de silencios en el aula-zoom. A continuación, menciono unos pocos.

El mutismo colectivo es parte del no lugar. La universidad como espacio se compone de múltiples sonidos sobrepuestos que conforman un paisaje sonoro. Uno de ellos es el barullo o lo que en el Río de la Plata se denomina con un tono más alegre, bochinche. Un conjunto de voces desordenadas y ruidosas que en cierta medida se tornan inteligibles en su particularidad, pero que en conjunto crean un ambiente sonoro de tono festivo que ensambla vitalidad. Ese barullo se da en los pasillos, en las cafeterías, en la intersección de los múltiples itinerarios individuales que hacen la vida de la universidad. Es el lugar habitado. Es fácil de identificar, al grado que siguiendo los momentos de barullo en una facultad se puede saber con relativa exactitud la hora del día. En el espacio digital el primer sonido que se controla es el 
barullo. Basta que un ruido excesivo salga de un cuadro determinado para que se le haga mutis con el clic que apaga su micrófono. Incluso se le invita a guardar silencio, no a él en específico, sino a su ambiente sonoro particular. Pero más allá de ello, lo relevante aquí es que se calla al producto unificado de voces diversas. No hace falta proscribirlo, el propio diseño de la plataforma lo inhibe.

Otro mutismo es cuando un estudiante no habla porque su propio espacio sonoro se lo impide. He mencionado el aviario, pero también en la identificación de sonidos tónicos se registraron los breves e intensos cantos de gallos de pelea, el abejorreo de un transporte público o el runrún de centenar de motores en una esquina de la ciudad que acallan la voz de quien pretende hablar. Uno muy significativo para ejemplificar el sonido como producto de la desigualdad educativa apareció cuando solicité a una alumna responder a una pregunta. $\mathrm{Al}$ abrir su micrófono, el retumbar de un bombo, dos tom y un hi hat golpeados con el ímpetu de una baquetas juveniles y despostilladas penetraron nuestros oídos. Una batería encerrada en un cuarto solo, ella habla y solo ella escucha. "Es mi hermano ensayando. Por eso no participo, profesor", se excusó. Pero la calle que impone mutis también es desigualdad. En las paradojas contemporáneas, en el aula-zoom no hay suspensión para pensar lo escolar, pero es por Zoom la única forma en que el o la estudiante pueden atarse a la escuela, aunque sea solo en tránsito.

La escuela siempre ha hecho callar. Promueve el silencio por control, pero también como posibilidad de lo escolar. "En las instituciones escolares, confesionales y después laicas, el silencio se ha impuesto desde los inicios de los tiempos modernos. Se concibe a la vez como señal de respeto al maestro y al profesor, como prueba de un autodominio que evita la dispersión y como requisito para la atención" (Corbin, 2019: 67). Pero, en la escuela, el silencio posee sonidos. Como mínimo los ruidos corporales. No todos por supuesto. El proceso civilizatorio de la sociedad burguesa recluyó al espacio privado las flatulencias, borborigmos y demás. La escuela, como parte de este proceso regulador, los encierra también en el baño, con la excepción de algún chico de secundaria que, en una masculinidad exhibicionista transgrede el silencio áulico con un atronador eructo, al que le acompañan no menos transgresoras carcajadas. Pero hay otros que no callan como las pisadas sordas, el suspiro cansado, el estornudo inesperado, el frotarse el ojo irritado y tantos otros ruidos que solo puedo recuperar por la memoria ya que el aula-zoom los silenció. El mutismo corporal solo es posible en la escuela como no lugar, en universidades sin cuerpos. Y con los cuerpos se van los sentidos, la sexualidad, el movimiento, la espacialidad. Pero recuérdese, mi intención aquí es describir y dar posibles puntos de fuga hacia futuros inciertos, no explicar o fijar. Por eso, no sé si vamos hacia una escuela sin cuerpos, pero sí sé que por lo menos en el interregno pandémico, lo ha sido.

Silencios hay demasiados (Corbín, 2016) y no dispongo aquí de los caracteres suficientes para profundizar en ellos. Estoy seguro de que el mutis y el mutismo son más representativos de un aulazoom que la voz y las voces. Por eso, quiero concluir este breve apartado con el problema central del uso del sonido en la escuela virtual como referente empírico para el estudio de las relaciones pedagógicas: la yuxtaposición y la imbricación de paisajes sonoros en un no lugar que crea instantes de sonidos compartidos e incontables momentos no compartidos. En la mayoría del tiempo en Zoom no compartimos silencios. El producido por los micrófonos apagados no es un silencio común a los asistentes, que te hace retrotraerte a tus propios pensamientos en medio de otro e incluso con otros, como en una biblioteca, en una obra de teatro o en el vagón semivacío del metro. Tampoco es el silencio que te deja escuchar los pequeños y aislados sonidos de una clase, una respiración, un papel estrujado, el carraspeo de una garganta seca. En el aula-zoom estamos en un silencio del otro. Es como ese silencio encerrado en los audífonos, cuando solo escuchamos la inhalación seca y lejana de nuestra respiración. Es el silencio digital que solo se escucha a sí mismo. 


\section{Escucha/escuchas}

Hay ruidos que no escuchamos, pero no hay educación sin escucha, sin atender al otro. ${ }^{6}$ Por eso, el silencio en la escuela dista mucho de ser mero control u opresión. En infinidad de casos es una condición irreductible para el aprendizaje. "Callar es también mostrar que uno se mantiene disponible para la escuela" (Corbin, 2019: 71), "callar, en efecto, permite escuchar bien" (Corbin, 2019: 67) y es parte de los rituales que predisponen a los sujetos para el aprendizaje (Meirieu, 2016). Es, también, activo (Luri, 2020). Por eso escuchar y oír tienen connotaciones diferentes. Con el silencio pensamos, pero también escuchamos. En la educación a distancia no hay escucha compartida. Está fragmentada. Hay tan diversas y disímiles formas de escuchar que de nuevo lo común se diluye en la singularidad. También, los ambientes sonoros diversos de cada participante, cruzados fundamentalmente por la condición de clase social, posibilitan u obstaculizan la escucha escolar.

Como sucede con la voz, escuchar tiene variadas significaciones, multiplicadas a su vez por las condiciones producidas por las tecnologías sónicas. Uno de ellos, "listening in" (Rice, 2015: 100), es la posibilidad subrepticia, clandestina, policiaca de escuchar o intervenir las llamadas telefónicas. En esa misma dirección, Michelle Kasprzak clama en su Anti-video chat Manifesto "Let's not forget my comrades, WE MUST QUESTION who is also present on these calls?" (2020: s/p; mayúsculas del original). Por extensión, el aula-zoom también es la escuela escuchada por alguien más allá, ${ }^{7}$ con audífonos, anotando no sabemos qué. También está el escuchar con atención de un terapeuta, un amigo o un estudiante, este último acompañado en muchas ocasiones del imperativo docente ¡Escuchen! $O$ el escuchar de un concierto o la radio, más vinculado con la audiencia. En esta pluralidad, escuchar se alejó también del propio acto de escuchar, como "escucha tu cuerpo" o "escucha las necesidades de aprendizaje de tus estudiantes". Finalmente, se puede enseñar y por tanto se puede aprender a escuchar. Sea como sea, los matices de escucha hacen referencia a los niveles de agencia auditiva (Rice, 2015: 101). La escucha así está estrechamente vinculada en el ámbito escolar a la atención. Pero también lo está al control escolar.

Si a partir de Jacques Attali (1995: 16) se piensa el sonido en la escuela como parte del ejercicio de poder, el control docente en el aula presencial depende en buena medida de su oído. Mientras escribe en el pizarrón puede identificar la voz que murmulla o el volumen de un equipo de trabajo dentro de lo tolerable o no. Esto se pierde en el aula-zoom. El docente deja de escuchar la voz del estudiantado que no está dirigida directamente a él. En un caso, veo a una estudiante con la cámara encendida y el micrófono apagado charlar con alguien más que está de pie frente a ella, del que se visualiza un brazo y el tronco. La alumna gesticula, abre la boca y sus labios se mueven emitiendo palabras. Ríe. Yo no la escucho y no tengo forma de controlar esa charla, ya no efectuado con el o la compañera, sino con alguien externo al aula. Su voz y su escucha están fuera del espacio escolar, pero su imagen no. La pérdida de autoridad sobre el sonido puede interpretarse como un desgajamiento del poder docente, pero eso me parece secundario. Tampoco pensemos en un estado subversivo o de resistencia ideal, porque el ruido, la charla, están donde está cada sujeto y no en el espacio virtual. Lo que imposibilita compartir un paisaje

\footnotetext{
${ }^{6}$ A modo de doble aclaración. La primera es que hay sonidos con frecuencias altas y bajas que nuestras capacidades auditivas no son capaces de percibir. Creer que un árbol hace ruido cuando cae en medio del bosque solo si un humano lo escucha es una visión antropocéntrica del sonido (Schafer, 2013) e, incluso, de un especismo insostenible. La segunda es que la escucha se entiende aquí como poner atención a lo que dice el otro, sea lingüístico o extralingüístico. Esa escucha es central en el proceso educativo. En este sentido, un individuo con debilidad auditiva posee tanta educabilidad como cualquier otro.

7 Esta condición tampoco es nueva del todo. Hay formas policiacas diversas para escuchar lo que se habla en un aula, especialmente en la universitaria. También los teléfonos celulares y su capacidad cada vez mayor de grabar lo que sucede en el aula han expuesto las relaciones pedagógicas a un público infinitamente más amplio que el meramente escolar. Lo nuevo está en que ahora es mucho más fácil hacerlo a la distancia y somos nosotros, docentes y estudiantes, quienes crean las condiciones para esta escucha.
} 
sonoro es que nos convertimos en una comunidad áulica sin escucha, pulverizada y, por tanto, en una escuela sorda.

Escucharse uno al otro da la certeza de presencia. Sin embargo, las modificaciones a las formas de escuchar en un aula de clases producidas por la tecnología dislocan la presencia con cascadas de incertidumbre. Por supuesto, si tomamos en cuenta la radio, el teléfono y la grabación de sonidos las formas de escuchar lejos del lugar donde se produce un ruido, una música o una palabra antecede y desborda a la escuela digital. Cuando se alzaba la voz en las llamadas de larga distancia de mi infancia se hacía para certificarse de que se era escuchado, como si gritaran de una ribera a otra de un río caudaloso. Hoy, aunque escuché docentes que siguen alzando notablemente la voz en Zoom, lo que se necesita es la comprobación de la propia presencia (Abrahams y Pinheiro, 2020). Es el cotidiano ¿̇se me escucha? o ¿me escuchan? Es decir, la incertidumbre que produce el no saberse escuchado posiciona al aula-zoom como un espacio de escucha/no escucha intermitente y aleatorio. Esto es extensivo al proceso educativo en sí. Sin saberse escuchado y sin escuchar, no hay escuela.

Es seguro que las formas de escucha de los estudiantes han cambiado significativamente. Con las grabaciones y mis diarios de campo no es posible saber cómo escuchan. Solo sé cómo escucho yo. Pero el registro de sonidos de fondo y la atención visual a los lugares donde se encuentra el estudiantado permiten suponer que la escucha de la clase no es el único estímulo auditivo al que responden y, quizá, en muchos de ellos ni siquiera es el protagónico. No se trata del multitask, tan enemigo del estudio (Desmurget, 2020), sino de la imposibilidad de fijar la atención en el conocimiento que se comparte dentro del aula. Pensaría yo, a manera de hipótesis, que la escucha escolar en el aula-zoom se desliza cada vez más hacia la difusión unilateral del docente que mezcla su voz con la de la radio del vecino, el pitido del claxon y la lavadora automática. Hoy se escucha una clase como un podcast, pero con pobre fidelidad. Así, siguiendo el sonido, podemos ver que las panaceas de la computadora como mediadora de la experiencia escolar más que promover la comunidad, el diálogo y la escucha, se dirigen en sentido opuesto. La educación personalizada que no escucha o que solo se escucha a sí misma no es educación, porque no hay otra.

\section{Impresiones finales}

El aula-zoom es un no lugar privado. Toda mediación auditiva atraviesa una plataforma que es propiedad de un gran corporativo. De esta manera la educación pública se da en un espacio mediado por el capital que, con su propia eficiencia, crea la geometría digital que permite o no determinados sonidos y, con ellos, valora culturas, relaciones, saberes y sentidos de lo educativo. En otras palabras, parte de la tensión auditiva entre la singularización del paisaje sonoro de un espacio colectivo y su imposibilidad de crear lo común es condicionado por las formas privadas de pensar la relación pedagógica. Otra parte, por supuesto, es la pandemia y el confinamiento que creó nuevas barreras auditivas en el hogar. Pero en México esta situación ya cambió. Se han recuperado las calles y los negocios, parcialmente la escuela primaria y secundaria y a cuentagotas las instalaciones universitarias. Cabe suponer, quizá sobre interpretando las impresiones sonoras del aula-zoom, que la tendencia hacia la privatización de la relación educativa que impide las voces y mantiene la voz, simplifica el mutis y reduce la escucha común para descomponerse en escuchas singularizadas, privatiza la relación pedagógica. Privado es el medio, privado es el poder, privado es el paisaje sonoro. Privada está la escuela, de lo común.

Este nuevo paisaje sonoro escolar permite identificar cambios notables y sutiles de las relaciones pedagógicas universitarias en pandemia. El primero es la pérdida de paisajes sonoros complejos y específicos de un lugar como es la escuela, con sus sonidos tónicos de campana, barullos, risas y demás. Este cambio pasa de la inmersión de lo común a la virtualización de un instante comunicativo. Otra 
transformación auditiva vinculada con la pérdida de la diversidad sonora es que la descontextualización del saber escolar y su tiempo de suspensión se pierden, amenazando la especificidad del acto escolar y sus características educativas. Asimismo, este no lugar crea redes instantáneas de comunicación, pero no da posibilidad a lo común o, como sostiene Augé "el espacio del no lugar no crea identidad ni relación, sino soledad y similitud" (2008: 107). Finalmente, la escucha como acción irreductible del acto educativo queda ensordecida. Pero también hay continuidades escolares amplificadas: el poder docente sobre el habla áulica, la posibilidad física de hacer callar, la masificación y, como tanto se escucha en la estridencia de los gallos, la batería o la lavadora automática, la desigualdad educativa. Esto es lo que pude escuchar, pero aún quedan muchas preguntas por responder. Por ejemplo, siguiendo la idea de la acustemología de Feld (2013) o el sonido como producción de conocimiento, falta analizar qué conocimiento escolar se produce a través de los timbres digitales y la pluralidad de fondos sonoros. El no lugar, las transformaciones de las relaciones pedagógicas y la conservación de prácticas sustantivas de la cultura escolar están produciendo un fenómeno, paradójico sí, de prácticas de escolarización sin escuela o, en otras palabras, la disolución del monopolio de la escuela como productora de escolarización.

Pero también queda pendiente discutir si estos cambios son buenos para la educación basada en los procesos de escolarización. Valorar si es buena o no esta educación parece en primera instancia anacrónico y moralista. Pero, si damos crédito a Gert Biesta (2016a), esta pregunta parecería ser tan importante, tan necesaria para la producción de lo común, que la era de la evaluación, la rendición de cuentas, el aprendizaje, la calidad y el presente continuo del aula-zoom se han encargado deliberadamente de desprestigiarla. ¿Qué es buena educación para una colectividad? es un pregunta compleja y demasiado amplia para discutir aquí. Biesta retoma a Arendt, Marion Iris Young y a Jacques Ranciere, para sostener la posibilidad de enseñar a los recién llegados que el mundo ya estaba aquí, que una democracia deliberativa es una buena forma de igualdad y que la igualdad de inteligencias nos permite producir procesos de subjetivación emancipadoras (2016a, 2016b). Esto, claro está, no sucede en el aula-zoom. Pero más aún, la imposibilidad de crear un lugar común, un paisaje sonoro compartido, hace imposible la escucha y, sin ella, no hay buena educación posible. De esta manera, el estudio del sonido en los procesos de escolarización virtuales forzados por la pandemia nos arroja un futuro posible o por lo menos un pasado y un presente experimentado, en el que el encierro individual en una barrera sonora corre el riesgo de terminar en una educación desde del yo, para el yo y sobre el yo. Y donde no hay otro ¿qué de educativo tiene esta educación? ¿Suena a buena educación?

\section{Bibliografía}

ABrahams, Annie y Daniel PinHeIRo (2020), "Embodiment and Social Distancing: Projects", Journal of Embodied Research, vol. 3, n. ${ }^{\circ}$ 2, pp. 27-52). Consultado en <https://jer.openlibhums.org/article/id/7657/> (06/11/2021).

ANDERSON, Karen (2004), “The Problem of Classroom Acoustics: The Typical Classroom Soundscape is a Barrier to Learning", Seminar in hearing, vol. 25, n. . 2. pp. 117-127.

AOKI, Ted, PINAR, William F. y Rita L. IRWIN (2012), Curriculum in a new key: the collected works of Ted T. Aoki. New York, Routledge.

ATTALI, Jacques (1995), Ruidos Ensayo sobre la economía política de la música. Ciudad de México, Siglo XXI.

AugÉ, Marc (2008), Los no lugares. Mizraji, Margarita (trad.). Barcelona, Gedisa.

BAQUero, Ricardo, Diker, Gabriel y Graciela FrIGERIO (coords.) (2007), Las formas de lo escolar. Buenos Aires, Del Estante.

BIESTA, Gert (2016a), Beyond Learning: Democratic Education for a Human Future. Abingdon, Routledge. 
BIESTA, Gert (2016b), The beautiful risk of education. New York, Routledge.

CÁRDENAS-SOLER, Ruth y Dennys MARTÍNEZ-CHAPARRO (2015), "El paisaje sonoro, una aproximación teórica desde la semiótica" Revista de investigación, desarrollo e innovación, vol. 5, n. . 2, pp. 129-140.

Chevallard, Yves (1991), La transposición didáctica. Del saber sabio al saber enseñado. Gilman, Claudia (trad.). Buenos Aires, Aiqué.

CORBIN, Alain (2019), Historia del silencio: del Renacimiento a nuestros días. Bayod Brau, Jordi (trad.). Barcelona, Acantilado.

CORBIN, Alain (1998), Village Bells: Sound and Meaning in the Nineteenth-Century French Countryside. New York, Columbia University Press.

CUESTA, Raimundo (1998), Clio en las aulas. La enseñanza de la bistoria en España entre reformas, ilusiones y rutinas. Madrid, Akal.

De CerTeau, Michel (2000), La invención de lo cotidiano. 1 Artes de hacer. Pescador, Alejandro (trad.). Ciudad de México, Universidad Iberoamericana-ITESO.

Desmurget, Michel (2020), La fábrica de cretinos digitales: Los peligros de las pantallas para nuestros hijos. Cortés Fernández, Lara (trad.). Barcelona, Península.

DUSSEL, Inés y Marcelo CARUSO, (2006), La imención del aula: mna genealogia de las formas de enseñar. Buenos Aires, Santillana.

Eisenberg, Andrew J. (2015), "Space” en NovaK, David, and SAKAKEENy Matt (2015), Keywords in sound. Londres, Duke University Press, pp. 193-207.

FELD, Steven (2013), "Una acustemología de la selva tropical”, Revista Colombiana de Antropología, vol. 49, n. . 1, pp. 217-239.

FREINET, Célestine (1978), Consejos a los maestros jóvenes. Colomé, Josep (trad.). Barcelona, Laia.

FreIRE, Paulo (2017), Pedagogía del oprimido. Mellado, Jorge (trad.). Ciudad de México, Siglo XXI.

GERSHON, Walter (2011), "Embodied knowledge: Sounds as educational system”, Journal of Curriculum Theorizing, vol. 27, n. ${ }^{\circ}$ 2, pp. 66-81.

GERSHON, Walter (2017), Sound curriculum: sonic studies in educational theory, method, \& practice. New York, Routledge.

GERSHON, Walter y Peter Michael APPELBAUM (2019), Sonic studies in educational foundations: echoes, reverberations, silences, noise. Milton, Routledge.

HAN, Byung-Chul (2021), No-cosas: quiebras del mundo de hoy. Chamorro Mielke, Joaquín (trad.). Barcelona, Penguin Random House.

HeLMrEICH, Stefan (2010), "Listening against Soundscapes”, Anthrapology News, vol. 51, n. o 9, p. 10.

JACKSON, Philip W. (1996), La vida en las aulas. Solana, Guillermo (trad.). Madrid, Morata.

KASPRZAK, Michelle (2020), Anti-Video-Chat-Manifesto. Consultado en <https://michelle.kasprzak.ca/blog/writinglecturing/anti-video-chat-manifesto $>(29 / 10 / 2021)$.

LOVINK, Geert (2020), “The anatomy of Zoom fatigue”, Euroæine. Consultado en $<$ https://www.eurozine.com/the-anatomy-of-zoom-fatigue/>(29/10/2021).

LURI, Gregorio (2020), La Escuela no es un parque de atracciones: una defensa del conocimiento poderoso. Barcelona, Ariel.

MAsschelein, Jan y Maarten Simons (2014), Defensa de la escuela: una cuestión pública. Rodríguez Esteban, Antonio Francisco (trad.). Buenos Aires, Miño y Dávila.

MCLAREN, Peter (1995), La escuela como un performance ritual: hacia una economía politica de los símbolos y gestos educativos. Ciudad de México, Siglo XXI. 
MeIRIEU, Philippe (2016), Recuperar la pedagogía: de lugares comunes a conceptos claves. Birgin, Alejandra (trad.). Buenos Aires, Paidós.

MONTESSORI, María (2014), El método de la pedagogía científica: aplicado a la educación de la infancia. Madrid, Biblioteca Nueva.

PINAR, William (2016), La teoría del curriculum. Mora, Edmundo (trad.). Madrid, Narcea.

PLÁ, Sebastián (2020a) "La pandemia en la escuela: entre la opresión y la esperezna”, en CASANOVA CARDIEL, Hugo (coord.), Educación y pandemia: una visión académica. Ciudad de México, IIUSE_UNAM, pp. 30-38.

PLÁ, Sebastián (2020b), “Apología por la escuela”. Perfiles Educativos, vol. 170.

PLÁ, Sebastián (en prensa), "Las escuelas del futuro. Imágenes para la post-pandemia”, Revista de la Facultad de Filosofia y Letras, UNAM.

Rice, Tom (2015), “Listening”, en NovaK, David, y SAKAKEENy Matt (2015), Keywords in sound. London, Duke University Press, pp. 99-111.

Samuels, David, Meintjes, Louise, OchoA, Ana Maria, y Thomas Porcello (2010), "Soundscapes: Toward a Sounded Anthropology." Annual Review of Anthropology, vol. 39, pp. 329-345.

SCHAFER, Murray (1998), El nuevo paisaje sonoro: un manual para el maestro de música moderno. Shultis, Juan (trad.). Buenos Aires, Ricordi Americana.

SCHAFER, Murray (2013), Elpaisaje sonoro y la afinación del mundo. Cazorla, Vanesa G. (trad.). Barcelona, Intermedio.

ThOMPSOn, Emily (2012), "Sound, Modernity and History", en Sterne, Jonathan (ed.), The sound studies reader. Abingdon. New York, Routledge, pp. 117-129.

TYaCK, David y Larry CuBAn (1995), Tinkering toward Utopia. A Century of Public School Reform. Cambridge, Massachusetts, Harvard University Press.

VIÑAO, Antonio (2002), Sistemas educativos, culturas escolares y reformas: continuidades y cambios. Madrid, Morata.

WeIDman, Amanda (2015), "Space” en Novak, David and Matt Sakakeeny, Keywords in sound. London, Duke University Press, pp, 232-245. 